\title{
Description of a New GLA Gene Variant in a Patient with Hypertrophic Cardiomyopathy. Is it Fabry Disease?
}

\author{
Marcelo Imbroinise Bittencourt ${ }^{\circledR}$ \\ Hospital Universitário Pedro Ernesto da Universidade do Estado do Rio de Janeiro, Rio de Janeiro, RJ - Brazil \\ Short editorial related to the article: GLA Gene Mutation in Hypertrophic Cardiomyopathy with a New Variant Description: Is it Fabry's Disease?
}

Hypertrophic cardiomyopathy $(\mathrm{HCM})$ is the most common monogenic cardiovascular disease in Brazil, with a prevalence of approximately 1:500 individuals. The autosomal dominant inheritance pattern is the most common one. More than 20 genes have been reported as being associated with the disease, and most of them encode sarcomeric proteins. ${ }^{1,2}$

Fabry disease (FD) is a lysosomal storage disorder caused by $\alpha$-galactosidase- $A$ deficiency due to a mutation in the GLA gene, with X-linked inheritance. It causes alterations in multiple organs, including the heart, mimicking $\mathrm{HCM}^{3}$

In a publication by Favalli et al., ${ }^{4}$ a prospective 10-year FD screening study, hypertrophy with wall thickness $>13 \mathrm{~mm}$ was the most common finding of the disease, occurring in approximately $50 \%$ of individuals with mutations in the GLA gene, followed by acroparesthesia and renal failure. ${ }^{4}$

A better understanding of the disease prevalence has been attained as its screening has been carried out in several populations. A Chinese study published in the past decade Indicates a prevalence of 1: 1600 men. ${ }^{5}$ Some mutations can cause the disease with limited heart manifestations, and this has already been reported in previous studies. ${ }^{6,7}$ The hypertrophy pattern may be useful to differentiate FD from HCM, but it is not an easy task. In HCM, the distribution of the left ventricular hypertrophy is characteristically asymmetric and heterogeneous, with several possible phenotypes. In FD, the hypertrophy is typically concentric, without obstruction of the left ventricular outflow tract, and the tapering of the basal portion of the left ventricular posterior wall is a characteristic of the final stage of the disease.

In the current issue of the Brazilian Archives of Cardiology, Chaves-Markman et al. ${ }^{8}$ found mutations in the GLA gene in

\section{Keywords}

Alpha-Galactosidase/deficiency; Fabry Disease/genetics; Fabry Disease/metabolismo; cardiomyopathy, Hypertrophic; Multiple Chronic Conditions.

Mailing Address: Marcelo Imbroinise Bittencourt •

Rua Dona Maria, 71 BL 1 Apto 902. Postal Code 20541-030, Vila Isabel,

Rio de Janeiro, RJ - Brazil

E-mail: mib@cardiol.br, marceloibittencourt@gmail.com

DOI: $10.5935 / a b c .20190126$
$6.7 \%$ of a cohort of $60 \mathrm{HCM}$ patients and reported a new variant, c.967C $>$ A (p.Pro323Thr), a missense mutation. This mutation has not been previously described, showing the originality of this work. ${ }^{8}$ Two other variants were described in this group of patients: c.937G $>\mathrm{T}$ (p.Asp313Tyr) and c.352C $>$ T (p.Arg118Cys). Interestingly, three of the four patients who had mutations in the GLA gene were females, a phenomenon also found in the article published by Csányi B et al., ${ }^{7}$ when they described the Ile239Met variant. ${ }^{7}$ This finding is little expected in patients with FD due to inactivation of the $\mathrm{X}$ chromosome in heterozygous women, resulting in milder symptoms. ${ }^{9}$

The main question of this article to be discussed is whether the new mutation is in fact responsible for the left ventricular hypertrophy. The detection of any rare missense variant represents a challenge for the conclusion of causality in any genetic condition, and FD is no different. Therefore, since only the analysis of the GLA gene was performed, one cannot rule out the possibility that another pathogenic variant in some other gene that causes HCM may be present in the patient in which the c.967C >A (p.Pro323Thr) variant was detected, as it was correctly highlighted in the study limitations.

Nevertheless, it is a very relevant finding, as the genetic alteration is in a highly conserved area of the protein and this has an impact on the definition of pathogenicity of a new variant. It should be emphasized that the patient had a transient ischemic attack among the extracardiac symptoms, without any documentation of atrial fibrillation, which could be associated with FD.

As emphasized by the author, the histopathological study is important for the diagnosis of FD, and it may help the groups that are discovering new variants of uncertain significance in the GLA gene to define its actual importance, especially in patients with the isolated cardiac form.

Every diagnostic method has its limitations, and the identification of a complex condition such as FD will increasingly require a multiple approach by integrating several modalities (genetics, biochemistry, imaging and histology), which will generate more evidence for each experiment. Definitely, the study carried out by Chaves-Markman et al. represents an important step in the genetic screening and knowledge acquisition of the association between HCM and FD in the Brazilian population. 


\section{References}

1. Task Force Members, Elliott PM, Anastasakis A, Borger MA, Borggrefe M, Cecchi F, et al. 2014 ESC Guidelines on diagnosis and management of hypertrophic cardiomyopathy: The Task Force for the Diagnosis and Management of Hypertrophic Cardiomyopathy of the European Society of Cardiology (ESC). Eur Heart J. 2014;35(39):2733-79.

2. Bittencourt MI, Mourilhe-Rocha R, Abanesi Filho FM. Hypertrophic cardiomyopathy. Rev Bras Cardiol. 2010;23(1):17-24.

3. Monserrat L, Gimeno-Blanes JR, Marin F, Hermida-Prieto M, GarcíaHonrubia A, Pérez I, et al. Prevalence of Fabry disease in a cohort of 508 unrelated patients with hypertrophic cardiomyopathy. J Am Coll Cardiol. 2007;50(25):2399-403.

4. Favalli V, Disabella E, Molinaro M, Tagliani M, Scarabotto A, Serio A, et al. Genetic screening of Anderson-Fabry disease in probands referred from multispecialty clinics. J Am Coll Cardiol. 2016;68(10):1037-50.

5. Lin HY, Chong KW, Hsu JH, Yu HC, Shih CC, Huang $\mathrm{CH}$, et al. High incidence of the cardiac variant of Fabry disease revealed by newborn screening in the Taiwan Chinese population. Circ Cardiovasc Genet. $2009 ; 2(5): 450-6$

6. Nakao S, Takenaka T, Maeda M, Kodama C, Tanaka A, Tahara M, et al. An atypical variant of Fabry's disease in men with left ventricular hypertrophy. N Engl J Med. 1995;333(5):288-93.

7. Csányi B, Hategan L, Nagy V, Obál I, Varga ET, Borbás J, et al. Identification of a Novel GLA Gene Mutation, p.lle239Met, in Fabry Disease with a predominant cardiac phenotype. Int Heart J. 2017;58(3):454-8.

8. Chaves-Markman AV, Markman M, Calado EB, Pires RF, Santos-Veloso MAO, Pereira CMF, et al. GLA gene mutation in hypertrophic cardiomyopathy with a new variant description: IsitFabry's disease? Arq Bras Cardiol. 2019;113(1):77-84

9. Mehta A, Hughes DA. Fabry Disease: Synonyms: Anderson-Fabry disease, alpha galactosidase A deficiency. In: Pagon RA, Adam MP, Ardinger HH, et al. eds. GeneReviews ${ }^{\circledR}$ [Internet]. Seattle, WA: University of Washington, Seattle; 1993-2017. [Cited in 2002 Aug 2]. Available from: https://www. ncbi.nlm.nih.gov/books/NBK1292/. 